\title{
Molecular triad containing a TEMPO catalyst grafted on mesoporous ITO electrode as photoelectrocatalytic anode for visible light-driven alcohol oxidation
}

Dr. Palas Baran Pati, ${ }^{a}$ Dr. Mohamed Abdellah, ${ }^{\text {b,c }}$ Dr. Stéphane Diring, ${ }^{a}$ Prof. Leif Hammarström, ${ }^{\mathrm{b}}$ Dr. Fabrice Odobel ${ }^{* \mathrm{a}}$

${ }^{a}$ Université de Nantes, CNRS, CEISAM UMR 6230, F-44000 Nantes, France. E-mail: Fabrice.Odobel@univ-nantes.fr

${ }^{\mathrm{b}}$ Department of Chemistry-Ångström Laboratories, Uppsala University, Box 523, SE75120 Uppsala, Sweden.

${ }^{c}$ Department of Chemistry, Qena Faculty of Science, South Valley University, 83523 Qena, Egypt

\begin{abstract}
Photoelectrochemical cell based on a semiconductor is among the most studied approach for artificial photosynthesis. Here, we investigated a recent concept based on the immobilization, on a mesoporous conducting ITO electrode (nano-ITO), of a molecular triad. The triad NDADI-P-Ru-TEMPO contained a ruthenium tris-bipyridine complex $(\mathrm{Ru})$ as photosensitizer, which was connected in one end to 2,2,6,6-tetramethyl-1-piperidine $\mathrm{N}$-oxyl (TEMPO) as alcohol oxidation catalyst, and in the other end to the electron acceptor naphthalene-dicarboxyanhydride-dicarboximide (NDADI). Light irradiation of the molecular triad (NDADI-P-Ru-TEMPO) grafted to nano-ITO performs selective oxidation of paramethoxy benzylalcohol (MeO-BA) to para-methoxy benzaldehyde in a carbonate buffer $(\mathrm{pH}$ $=10$ ) with a TON of $\sim 150$ after 1 hour of photolysis at a bias of $0.4 \mathrm{~V} v s$. SCE and the faradaic efficiency (FE) is found to be of $80 \pm 5 \%$. The photophysical study indicates that the photoinduced electron transfer from the Ru complex to NDADI is a slow process and must compete with direct electron injection into ITO to have a better performing system. This work sheds some light on some of the important features to design more efficient molecular systems for the preparation of photoelectrocatalytic cell based on the immobilized on conducting electrode of a "Catalyst-Dye-Acceptor" molecular array.
\end{abstract}


Keywords: Artificial photosynthesis, Photocatalysis, Photoelectrochemical cells (PEC), Alcohol oxidation, TEMPO catalyst, Molecular triad

\section{Introduction}

Artificial photosynthesis offers the great opportunity to reduce human foot-print and provide a sustainable development of human civilization thanks to the utilization of sunlight as a gigantic and renewable energy resource. ${ }^{[1]}$ Although the concept is still at the early stage in research laboratories, it will be surely developed at a large scale before the end of this century and will provide a new economical and more environmentally friendly energy landscape than the currently fossil fuel-based system. The concept of photoelectrochemical systems, based on catalysts grafted on electrodes, lies among the most studied and most attractive strategies to convert solar energy into storable chemical fuels by mimicking artificial photosynthesis. ${ }^{[2]}$
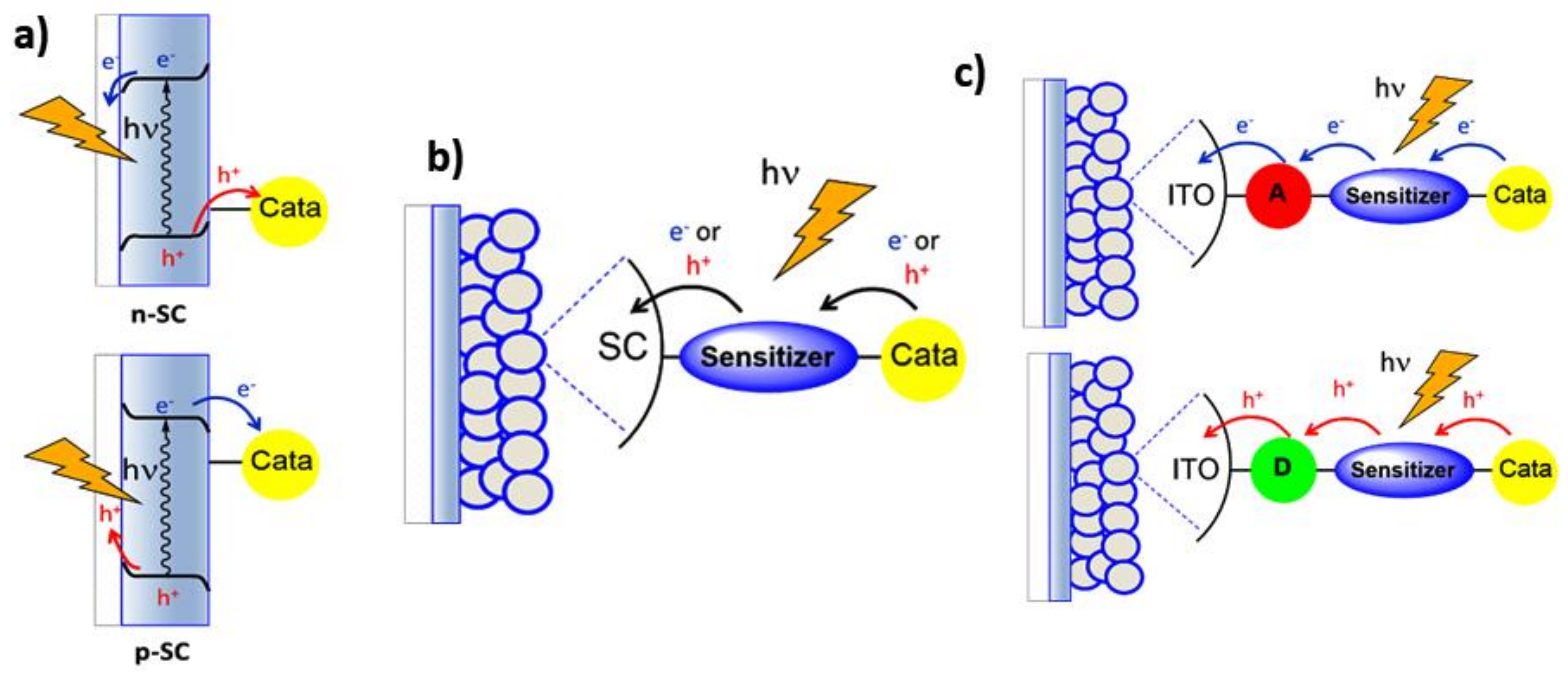

Figure 1. Schematic illustration the three types of photoelectrocatalytic systems usually investigated for artificial photosynthesis. a) classical PEC based on a low or medium bandgap semiconductor; b) dye-sensitized photoelectrosynthesis cell (DSPEC); and c) nanocrystalline indium tin oxide nanoparticles (nano-ITO) connected to three molecular components. In PEC (a), light irradiation promotes formation of an electron/hole pair inside the SC and the minority charge carriers (electrons for $\mathrm{p}$-SC and holes for $\mathrm{n}$-SC) migrate to the electrode/solution interface to activate the deposited catalyst (Cata), while the opposite 
charges are collected at the back contact. In DSPEC, light excitation of the sensitizer triggers charge injection into the SC (hole in p-SC and electron in $\mathrm{n}-\mathrm{SC}$ ). Then, the redox equivalent stored on the sensitizer shifts to the nearby catalyst to perform catalysis. The explanations of the operation principle in systems $\mathrm{c}$, are given in the main text.

In this context, several strategies have been explored (Figure 1). The most classical one is the photoelectrochemical cell (PEC), which comprises a low or medium bandgap semiconductor (SC), whose surface is functionalized by catalyst (Figure 1a). ${ }^{[2 b]}$ Typical examples are silicon photoelectrodes for proton reduction or water oxidation, which were abundantly investigated for several decades. ${ }^{[3]}$ Such an approach usually gives quite high photocurrent densities and therefore significant solar to chemical conversion efficiencies, but suffers from the quite general photocorrosion of low bandgap SCs during operation, which is particularly acute when the photoelectrode is in direct contact with the electrolyte. ${ }^{[4]}$ The second approach is the so called "dye-sensitized photoelectrosynthesis cell" (DSPEC), which is composed of a wide bandgap stable metal oxide $\mathrm{SC}$, such as $\mathrm{TiO}_{2}$ and $\mathrm{NiO}$. The metal oxide $\mathrm{SC}$ is sensitized by molecular dye, which is quenched by charge injection into the $\mathrm{SC} .^{[5]}$ The sensitizer is combined with an electrocatalyst either covalently bound to it or co-adsorbed with the dye on the surface of the SC (Figure 1b). So far, DSPECs provide much lower efficiencies than PECs, but as far as the SC stability is concerned, the photodegradation of the inorganic SC is not the main limitation because metal oxides are generally robust SCs in solution. A third approach relies on a conductor material generally composed of indium tin oxide nanoparticles (nano-ITO) connected to a three molecular component composed of: i) an electron acceptor (A) or electron donor (D); ii) a dye and iii) a catalyst (Figure 1c). Light excitation of the dye brings about a photoinduced charge separation with the nearby A or D, then the charge on A or D is scavenged by the nano-ITO electrode and finally the oxidized or reduced dye activates the catalyst. The latter approach is still in its infancy, motivating thus more investigations for the future design of efficient devices. Very recently, Meyer and co-workers reported interesting studies of systems based on this third approach by using metal phosphonate chemistry to fabricate, in a stepwise manner, the three component systems. ${ }^{[6]}$ This approach is particularly appealing over the classical PECs based on low bandgap SC, because the choices of such SCs are limited. Indeed, for PEC application, the SCs must display good absorbance in the visible region with high absorption coefficient with a high photostability in solution. In addition, another important and difficult property to meet is the 
formation of a long lived electron/hole pair after light excitation so that the minority photogenerated charge carriers in the SC efficiently reach the SC/electrolyte interface before recombination. ${ }^{[7]}$ As compared to the DSPEC approach, this third strategy is interesting, because it is relatively easier to accurately tune the LUMO (or HOMO) level of a molecular acceptor (or donor) via molecular engineering than the valence band (VB) or the conduction band $(\mathrm{CB})$ of an inorganic semiconductor. For example, with molecular acceptors it is possible to change the substituents to tune the energy position of its LUMO, hence its accepting power. Accordingly, the oxidative quenching of a dye displaying a high oxidation redox potential is workable by appending a strong electron acceptor such as naphthalene diimide substituted by electron withdrawing groups. ${ }^{[8]}$ As a consequence, it is possible to bypass the inherently low driving force electron injection reaction in the conduction band of a n-SC such as $\mathrm{TiO}_{2}$, which represents the limiting step with high oxidation potential sensitizers. ${ }^{[9]}$ Additionally, it is generally observed that the attachment of a dye directly on a conductor surface is not a good strategy to bring about photoinduced charge separation, because the dye is usually quenched by energy transfer or a fast charge recombination reaction is usually observed when photoinduced charge reaction happens. ${ }^{[10]}$

Synthetic molecular organic chemistry is a mature science and enables to design multicomponent molecular arrays with tailored properties. Accordingly, covalent molecular arrays permit to test very accurately the impact of molecular modifications on the overall properties of the devices. We were, thus, interested to investigate this third approach of photoelectrochemical systems with a covalently linked molecular tricomponent system to examine the feasibility and the key required parameters to build an efficient system. Towards this objective, we study a molecular triad composed of a dye (ruthenium complex) connected to the electron acceptor naphthalene-dicarboxyanhydride-dicarboximide (NDADI) to work in concert with an oxidation catalyst (TEMPO) be immobilized on surface of a conducting electrode (Figure 2). 


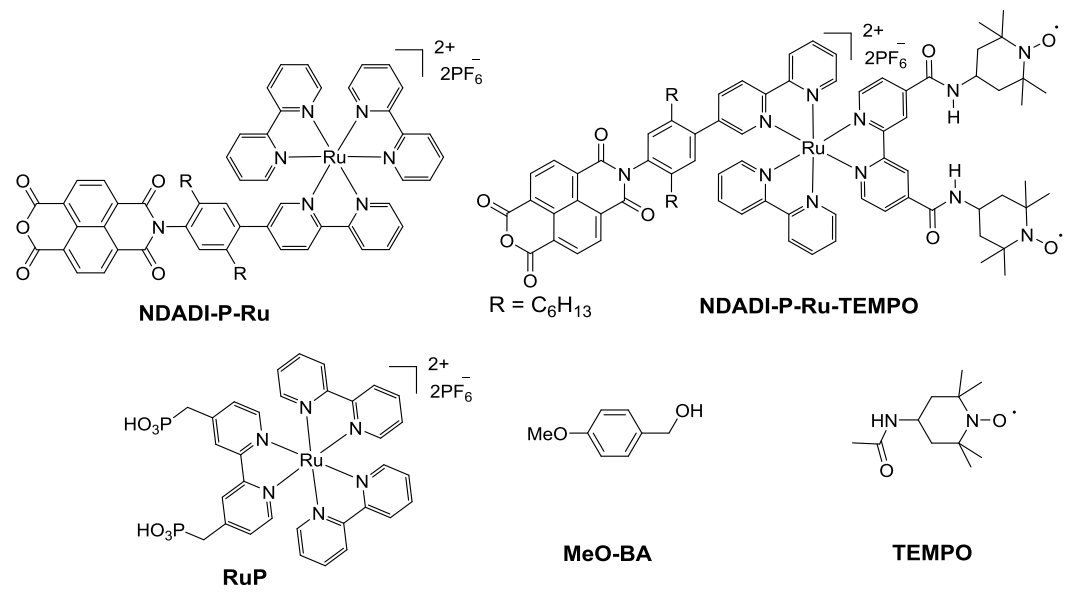

Figure 2. Molecular structures of compounds used in this study.

Inspired by the work of Wenger, ${ }^{[11]}$ who reported efficient photoinduced electron transfer from a ruthenium tris-bipyridine complex to a naphthalene diimide (NDI) with quite significantly long lived charge separated state $(\tau=20 \mathrm{~ns})$ in acetonitrile solution, we anticipated that the excited state of ruthenium complex in our systems could be also oxidatively quenched by the nearby NDADI. In this study, the NDI is replaced by a NDADI to enable direct grafting of the electron acceptor on a metal oxide electrode and to have a shorter distance between the naphthalene core and the electrode surface than with the Ru complex in order to promote electron shift reaction over charge recombination (NDADI'/ $\mathrm{Ru}^{\mathrm{III}}$ $\left.\rightarrow \mathrm{NDADI} / \mathrm{Ru}^{\mathrm{II}}\right)($ Scheme 1$) .{ }^{[6 \mathrm{c}]}$ Binding a dye through dicarboxyanhydride group was previously reported to graft perylene imide sensitizers on $\mathrm{TiO}_{2}$ surface for dye sensitized solar cells (DSSCs) and dye sensitized photoelectrosynthetic cells (DSPECs). ${ }^{[12]}$ NDADI being a more electron deficient moiety than NDI, it must constitute an even stronger electron acceptor. ${ }^{[13]}$ The dyad NDADI-P-Ru was prepared with the intention to generate the charge separated state (CSS) denoted $\mathrm{Ru}^{\mathrm{III}} / \mathrm{NDADI}^{-}$, similarly as that obtained in the dyad reported by Wenger and co-workers. ${ }^{[11]}$ The three component molecular array were grafted on a porous conducting electrode (here a mesoporous ITO film: m-ITO), whose role is to scavenge the electrons produced on the NDADI after light excitation of the dye with a suitable applied external potential (Scheme 1). Scheme 1 summarizes the expected working principle of the photoanode. 


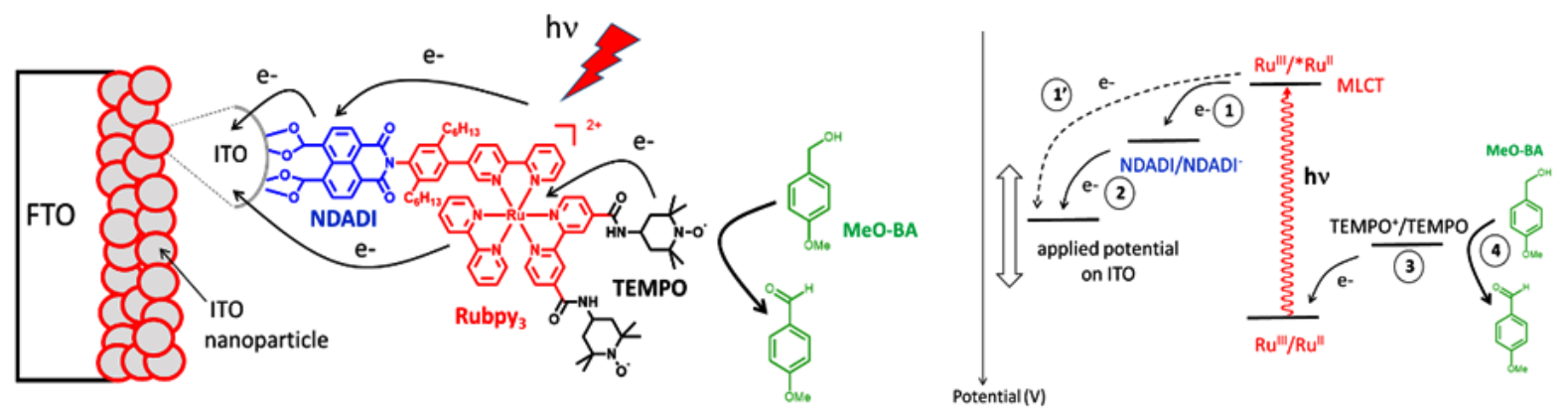

Scheme 1. Illustration of the photocatalytic anode and its working principle. In term of operation principle, the ruthenium complex MLCT excited state can decay either: i) by direct electron injection into ITO (1') followed by hole shift from Ru ${ }^{\text {III }}$ to TEMPO (3) and catalysis (4) or ii) the MLCT can first transfer an electron to NDADI (1) and then to ITO (2) followed by hole shift to TEMPO (3) before catalysis (4).

As a proof of concept, we chose to explore alcohol oxidation catalysis rather than the classically studied water oxidation. First, water oxidation is a sluggish reaction, which consumes high energy, because it requires high redox potential. It also necessitates four oxidizing equivalents (hence the absorption of four photons per $\mathrm{O}_{2}$ molecule) and usually necessitates costly catalysts often made of precious metals such as iridium and ruthenium. ${ }^{[14]}$ On the other hand, alcohol oxidation involves only two holes (therefore two photons), requires a much lower potential $(-0.143 \mathrm{~V}$ vs. NHE for benzyl alcohol oxidation versus 1.23 $\mathrm{V} v s$. NHE for water oxidation) ${ }^{[15]}$ and very importantly it produces carbonyl compounds, which have great economical added-values, because they represent an important class of intermediates for pharmaceutical and chemical industries. ${ }^{[16]}$ Recently, several groups have suggested the potential advantages to drive another reaction than water oxidation at the photoanode, because the latter often represents the bottleneck and the energy wasting process in most artificial photosynthetic systems. ${ }^{[17]}$ The low-cost, readily accessible TEMPO (2,2,6,6-tetramethyl-1-piperidine $\mathrm{N}$-oxyl) derivatives are well-known organocatalysts for selective and clean alcohol oxidation. ${ }^{[15,16 \mathrm{~b}, 18]}$ They have found widespread use in industrial and laboratory applications. Choi ${ }^{[19]}$ and Berlinguette et al. ${ }^{[20]}$ have successfully demonstrated a PEC devices which produce $\mathrm{H}_{2}$ while promoting a biomass derivative with TEMPO catalyzed oxidation of hydroxyl furfural at a $\mathrm{BiVO}_{4}$ photoanode. 
In this study, we have designed and characterized in details the properties of the molecular dyad (NDADI-P-Ru) and a triad with a covalently linked TEMPO catalyst (NDADI-P-RuTEMPO) (Figure 2). We demonstrated the photogeneration of highly oxidative Ru-center in NDADI-P-Ru dyad immobilized on mesoporous ITO electrode (m-ITO). Then, the triad NDADI-P-Ru-TEMPO was successfully implemented as a photocatalytic anode for benzyl alcohol oxidation to benzaldehyde and it gives interesting performances as a photocurrent density up to $180 \mu \mathrm{A} / \mathrm{cm}^{2}$ was measured under light irradiation. Altogether, this study sheds some light on some important features to design efficient molecular systems for the preparation of photoelectrocatalytic cell based on the third approach (Figure 1c). In particular, the photoinduced electron transfer from the dye to the molecular acceptor must be fast over the direct electron injection into ITO.

\section{Synthesis of the molecular components}

The synthetic route to the molecular dyad, NDADI-P-Ru is depicted in Scheme 2 and the detailed synthetic protocols are given in SI. Boc-protection of the amino group of compound $\mathbf{1}$ is followed by a Suzuki-Miyaura reaction with bis(pinacolato)diboron to provide the boronate compound $\mathbf{3}$ with $98 \%$ yield. The latter was then coupled with 5-bromo bipyridine 4 according to a second Suzuki-Miyaura cross-coupling reaction to afford compound 5 with moderate to good yield (70\%). After acidic cleavage of Boc-protecting group in compounds $\mathbf{5}$, the naphthalene-dicarboxyanhydride-dicarboximide (NDADI) was introduced in a quantitative yield by reaction with an excess of 1,4,5,8naphthalenetetracarboxylic dianhydride 7 to form the key ligand, 8. Finally, the complexation of bipyridine unit in 8 with $\mathrm{Ru}(\mathrm{bpy})_{2} \mathrm{Cl}_{2}$ gave desired dyad NDADI-P-Ru with about $56 \%$ yield after purification by size exclusion chromatography. 

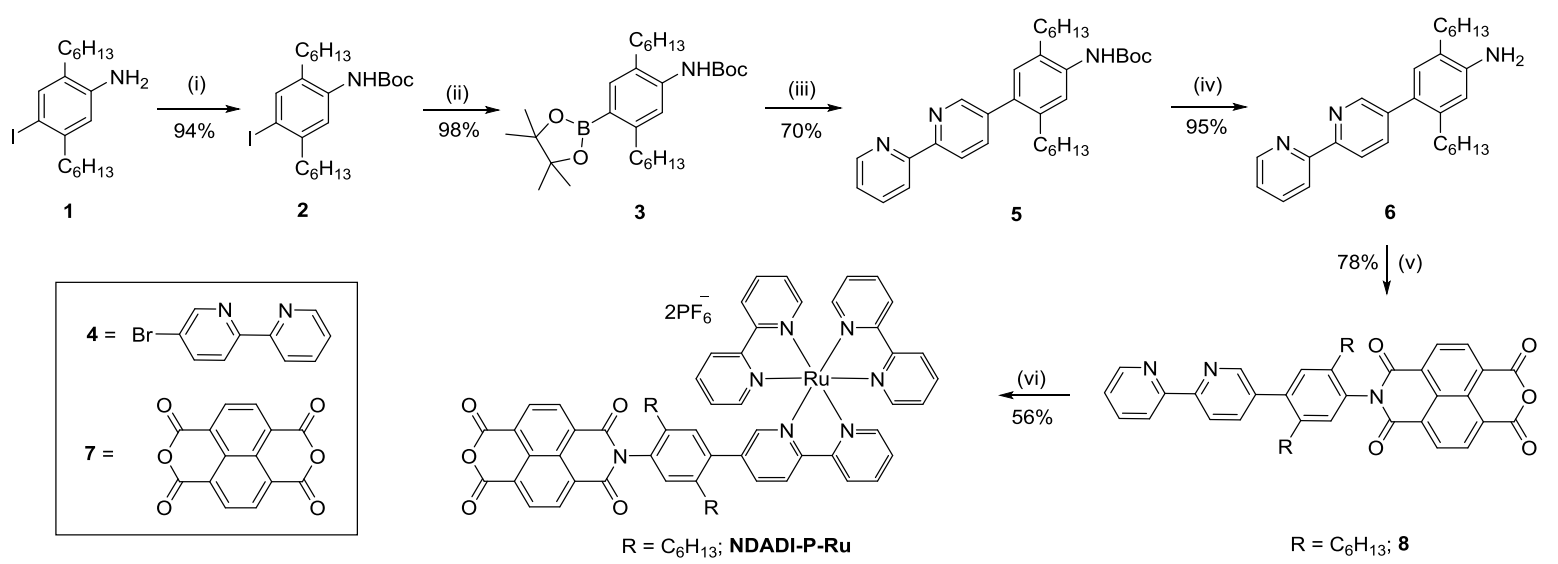

Scheme 2: Synthesis of molecular dyad NDADI-P-Ru; (i) (Boc) $2 \mathrm{O}$, toluene, reflux, 48 h; (ii) Bis(pinacolato)diboron, $\mathrm{Pd}(\mathrm{dppf}) \mathrm{Cl}_{2}, \mathrm{KOAc}, \mathrm{DMF}, 85{ }^{\circ} \mathrm{C}$; (iii) 4, $\mathrm{Pd}\left(\mathrm{PPh}_{3}\right)_{4}, \mathrm{Ba}(\mathrm{OH})_{2}$ DME/water (9/1), $120^{\circ} \mathrm{C}$; (iv) $\mathrm{HCl} / \mathrm{MeOH}(1 / 1)$, rt, 1 h; (v) 7, DMF, reflux, overnight; (vi) $\mathrm{Ru}(\mathrm{bpy})_{2} \mathrm{Cl}_{2}$, water/ethanol, reflux, overnight.

The synthesis of the triad NDADI-P-Ru-TEMPO is described in Scheme 3. The carboxylic acid groups of 4,4'-dicarboxylic acid-bipyridine 9 was first activated by thionyl chloride into acid chloride and then reacted with 4-aminoTEMPO $\mathbf{1 0}$ to form the amide linkages in the ligand 11 with $62 \%$ yield. ${ }^{[21]}$ By following a modified methodology earlier reported in the literature complex $\mathbf{1 3}$ is prepared through the reaction of the ligand $\mathbf{1 1}$ with chloro(p-cymene)bipyridine ruthenium $12 .{ }^{[22]}$ Then, by complexation of the bipyridine ligand 8 with compound 13 produce the desired triad NDADI-P-Ru-TEMPO with $43 \%$ yield.

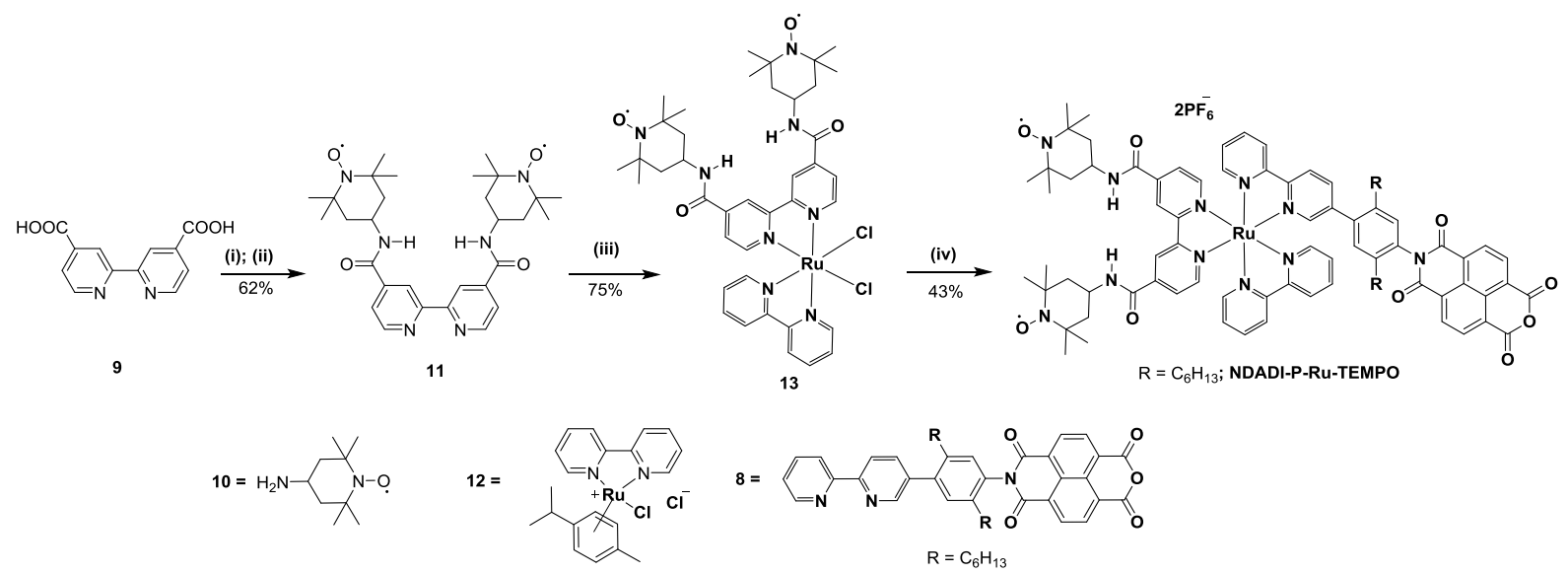

Scheme 3. Synthesis of molecular triad NDADI-P-Ru-TEMPO; (i) $\mathrm{SOCl}_{2}$, reflux, $48 \mathrm{~h}$; (ii) 10, triethylamine, THF, rt, 24 h; (iii) 12, DMF, $150{ }^{\circ} \mathrm{C}$, overnight; (iv) 8, water/ethanol, reflux, overnight. 


\section{UV-Vis absorption and electrochemical study}

Electronic absorption spectra of the dyad and the triad were first recorded in acetonitrile solution and compare to that of a regular $\mathrm{Ru}\left(\right.$ bpy) ${ }_{3}$ (Figure 3 ). The strong absorption band in the UV region is attributed to the $\pi-\pi$ transition on the bipyridine ligand and phenyl spacer. NDADI also contributes to absorption band in the region of 330-380 $\mathrm{nm}$. The broad absorption band in the visible region at $400-520 \mathrm{~nm}$ is assigned to the metal to ligand charge transfer (MLCT). However, this band is broader and red-shifted after introduction of the two TEMPO catalysts on the bipyridine in NDADI-P-Ru-TEMPO, most likely due to the presence of amide linkages which stabilize the LUMO of the resulting ligands. The absorption spectra of dyad and triad were also recorded on mesoporous ITO film (Figure S1). On the electrode, the wavelength absorption maximum of MLCT band undergoes a weak bathochromic shift in comparison to that observed in solution (Table 1), which is attributed to the different electronic environment. The redox potentials of the ruthenium complex and NDADI units were determined by cyclic voltammetry $(\mathrm{CV})$ both in acetonitrile solution and after chemisorption of the compounds on m-ITO films (Figure S2, Table 1). During the oxidative scan, the metal centred oxidation of the ruthenium complex is nicely observable as a reversible redox process $\left(\mathrm{E}_{\mathrm{Ox}}\left(\mathrm{Ru}^{\mathrm{III}} /^{\mathrm{II}}\right)=1.29 \mathrm{~V} v s\right.$. SCE). On the contrary, the oxidation potential of ruthenium is anodically shifted $\left(\mathrm{E}_{\mathrm{Ox}}\left(\mathrm{Ru}^{\mathrm{III}} /{ }^{I I}\right)=1.36 \mathrm{~V} v s\right.$. SCE) in the triad NDADI-P-Ru-TEMPO, reflecting thus the electron withdrawing character of the amide substituents on one bpy ligand. Moreover, the triad exhibits a supplementary oxidation process below that of the $\mathrm{Ru}^{\mathrm{III}} / \mathrm{II}$ couple at $\mathrm{E}=0.73 \mathrm{~V} v s$. SCE, which is assigned to the reversible oxidation of the nitroxide into the oxoammonium of TEMPO. ${ }^{[16 b, 23]}$ In the cathodic region, two reduction processes situated around -0.5 and $-0.7 \mathrm{~V}$ vs. SCE correspond to the

reduction of NDADI unit in agreement with the values reported on similar systems. ${ }^{[13]}$ The other irreversible reduction waves observed at more negative potentials correspond to ligand centred redox processes. Interestingly, after surface attachment of all the compounds on mITO electrodes the waves corresponding to the oxidation of the ruthenium centre is still nicely visible although the potential has been slightly modified, probably because the dielectric environment has changed (Table 1). It can be observed that the plots of the peak current density as a function of the scan rate yield a straight line, in agreement with an electrochemical process independent of the diffusion, because the electroactive species is grafted on the electrode surface (Figure S3). The amount of electroactive species loaded on the surface was calculated from the eq 1 where $i_{\mathrm{p}, \mathrm{c}}$ is peak current, $\Gamma$ is the surface coverage 
$\left[\right.$ mol.cm $\left.{ }^{-2}\right], v$ is the scan rate $\left[\mathrm{V} . \mathrm{s}^{-1}\right], \mathrm{F}$ is the Faradaic constant, $\mathrm{A}$ is the electrode surface area $\left[\mathrm{cm}^{2}\right]$, and $\mathrm{n}$ is the number of electrons transferred. The surface coverage of the electrode with NDADI-P-Ru and NDADI-P-Ru-TEMPO were found to be $15.5 \times 10^{-9} \mathrm{~mol} \mathrm{~cm}^{-2}$ and $11.2 \times 10^{-9} \mathrm{~mol} \mathrm{~cm}^{-2}$, respectively. ${ }^{[24]}$

$$
\frac{i_{p, c}}{A}=\frac{n^{2} F^{2}}{4 R T} v \Gamma(\text { eq. } 1)
$$

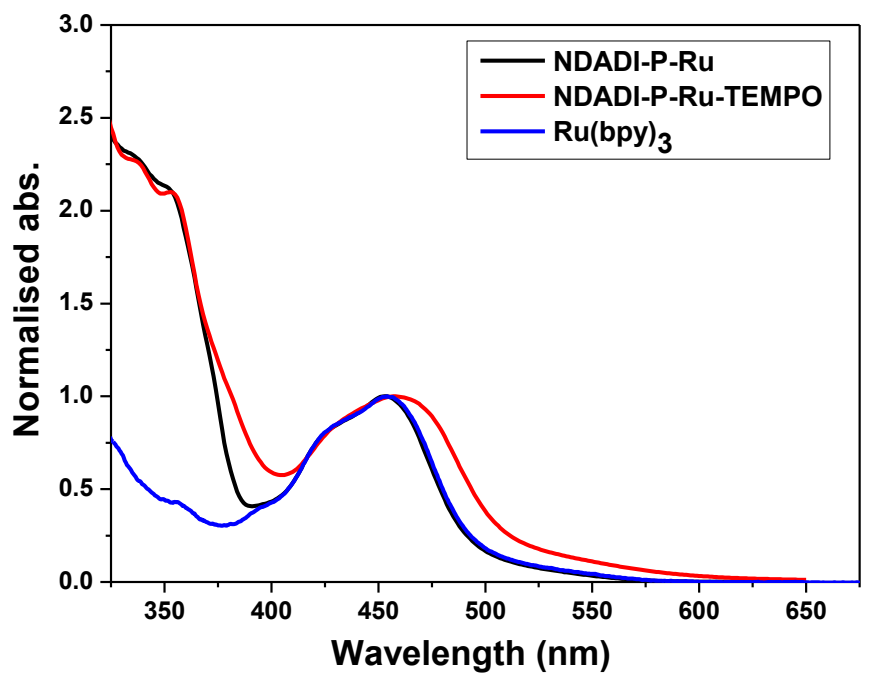

Figure 3. Electronic absorption spectra of NDADI-P-Ru, NDADI-P-Ru-TEMPO and $\mathrm{Ru}(\mathbf{b p y})_{3}$ recorded in acetonitrile solution.

Table 1. Maximum absorption wavelength of the MLCT transition in acetonitrile (solution) and on meso-ITO film (film) and redox potentials recorded in acetonitrile (solution) and on meso-ITO film (film) of the dyads and the triad. All potentials are referenced vs. SCE.

\begin{tabular}{|l|l|l|l|l|l|l|l|l|}
\hline Compound & \multicolumn{2}{|l|}{$\lambda_{\max }(\mathrm{MLCT})(\mathrm{nm})$} & \multicolumn{2}{l|}{$\mathrm{E}_{\mathrm{Ox}}\left(\mathrm{TEMPO}^{+/ 0}\right)$} & \multicolumn{2}{|c|}{$\mathrm{E}_{\mathrm{Ox}}\left(\mathrm{Ru}^{\mathrm{III}}{ }^{\mathrm{II}}\right)$} & \multicolumn{2}{l|}{$\mathrm{E}_{\mathrm{Red}}\left(\mathrm{NDADI}^{0}{ }^{\prime}\right)$} \\
\cline { 2 - 9 } & Solution & film & Solution & film & Solution & film & Solution & film \\
\hline $\begin{array}{l}\text { NDADI-P- } \\
\text { Ru }\end{array}$ & 453 & 466 & & & 1.29 & 1.33 & -0.45 & n.d. \\
\hline $\begin{array}{l}\text { NDADI-P- } \\
\text { Ru-TEMPO }\end{array}$ & 457 & 466 & 0.73 & 0.77 & 1.36 & 1.40 & -0.42 & n.d. \\
\hline
\end{tabular}

n.d. not determined see text. 
Although, the reduction process on the NDADI is visible as a wide wave in the voltamograms on ITO, the determination of the redox potential cannot be done accurately in spite of many attempts (Figure S2). The reason of this phenomenon is unknown at this moment. Finally, the redox potentials of each subunit composing the dyad and the triad along with the energy level of the MLCT excited state of the ruthenium complex $\left(\mathrm{E}^{00}{ }_{\text {MLCT }}\left(\mathrm{Ru}^{*}\right)\right)$ give access to the Gibbs free energy for each charge transfer step. $\mathrm{E}^{00}{ }_{\mathrm{MLCT}}\left(\mathrm{Ru}^{*}\right)$ was determined from the phosphorescence spectrum of the complex recorded in frozen ethanol glass at $77 \mathrm{~K}$ (Figure S10). Consistently with the red-shift MLCT absorption transition, NDADI-P-Ru-TEMPO displays a lower energy emission band than NDADI-P-Ru. First, the photoinduced electron transfer from the photoexcited ruthenium to NDADI (eq. 2) is thermodynamically favourable by $-0.36 \mathrm{eV}$ and $-0.20 \mathrm{eV}$ for NDADI-P-Ru and the triad NDADI-P-Ru-TEMPO respectively:

$$
\begin{aligned}
& \text { NDADI-P-Ru }{ }^{\text {II }}+\text { h } v \rightarrow \text { NDADI-P-*Ru }{ }^{\text {II }} \rightarrow \text { NDADI-P-Ru }{ }^{\text {III }} \\
& \Delta \mathrm{G}_{\mathrm{et}}^{0}=F\left(\mathrm{E}_{\mathrm{Ox}}^{0}\left(\mathrm{Ru}^{\mathrm{III} / \mathrm{II}}\right)-\mathrm{E}_{\mathrm{Red}}^{0}\left(\mathrm{NDADI}^{0} /\right)-\mathrm{E}^{00}{ }_{\mathrm{MLCT}}\left(\mathrm{Ru}^{*}\right) ; \Delta \mathrm{G}_{\mathrm{et}}^{0}\right. \text { : Free energy for }
\end{aligned}
$$

electron transfer reaction, $\mathrm{E}_{\text {Ox }}^{0}$ : Oxidation potential, $\mathrm{E}_{\text {Red }}^{0}$ : Reduction potential, $\mathrm{E}^{00}{ }_{\text {MLCT }}$ : $\mathrm{E}^{00}$ of metal to ligand charge transfer transition.

Second, the hole shift reaction from the oxidized ruthenium(III) centre to TEMPO (eq. 3), also displays a significant driving force of $-0.63 \mathrm{eV}$ in the triad NDADI-P-RuTEMPO.

\section{NDADI-P-Ru ${ }^{\text {III }}$-TEMPO $\rightarrow$ NDADI-P-Ru ${ }^{\text {II }}-$ TEMPO $^{+}$(eq. 3)}

$\Delta \mathrm{G}_{\mathrm{hs}}^{0}=F\left(\mathrm{E}_{\mathrm{Ox}}^{0}\left(\mathrm{TEMPO}^{+/ 0}\right)-\mathrm{E}_{\mathrm{Ox}}^{0}\left(\mathrm{Ru}^{\mathrm{III}} /{ }^{\mathrm{II}}\right)\right) ; \Delta \mathrm{G}_{\mathrm{hs}}^{0}$ : Free energy for hole shifting reaction, $\mathrm{E}^{0}{ }_{\text {Ox }}$ : Oxidation potential

Overall, the calculations of the Gibbs free energy changes the charge transfer processes support the feasibility of the electron transfer cascade from TEMPO to NDADI via the photoexcited ruthenium centre.

\section{Photoelectrochemistry in presence of sacrificial electron donor}

To probe the possible photoinduced electron transfer cascade from the ruthenium complex to the ITO electrode, linear sweep voltammetry (LSV) under chopped visible light irradiation 
was recorded with the dyad grafted on m-ITO electrodes (m-ITO|NDADI-P-Ru). These experiments were conducted in presence of triethanolamine (TEOA) acting as a sacrificial electron donor to regenerate the oxidized $\mathrm{Ru}^{\mathrm{III}}$ formed after photoinduced electron transfer (Figure 4). In presence of triethanolamine (TEOA), dyad displays photocurrent response with an onset potential at $0.1 \mathrm{~V} v s$. SCE confirming the electrons effectively flow from the solution to the ITO electrode; whereas without TEOA the absence of photomodulation indicates that TEOA is necessary to regenerate the oxidized ruthenium complex generated upon light excitation. An enhancement of photocurrent was observed upon increasing concentration of sacrificial electron donor and upon increasing the applied potential on the electrode (Figure S4). These results are consistent with a faster regeneration of $\mathrm{Ru}^{\mathrm{III}}$ when TEOA concentration is increased and with a more efficient electron collection by ITO nanoparticle as the electrode is more and more positively biased. Overall, these results demonstrate that the dyad is able to efficiently inject electron into ITO film upon visible light excitation, since photocurrent densities over $50 \mu \mathrm{A} / \mathrm{cm}^{2}$ can be reached with in presence of 50 $\mathrm{mM}$ of TEOA at $0.4 \mathrm{~V} v$ s. SCE applied bias with the dyad NDADI-P-Ru. These satisfying results encouraged us to make a step further and to design a triad that would exploit the photo-generated holes on $\mathrm{Ru}$-centres to perform oxidation catalysis. Therefore a triad (NDADI-P-Ru-TEMPO) is developed through functionalized NDADI-P-Ru with TEMPO catalyst to explore the possibility to perform light driven oxidation of benzyl alcohol substrates into aldehydes.

a)
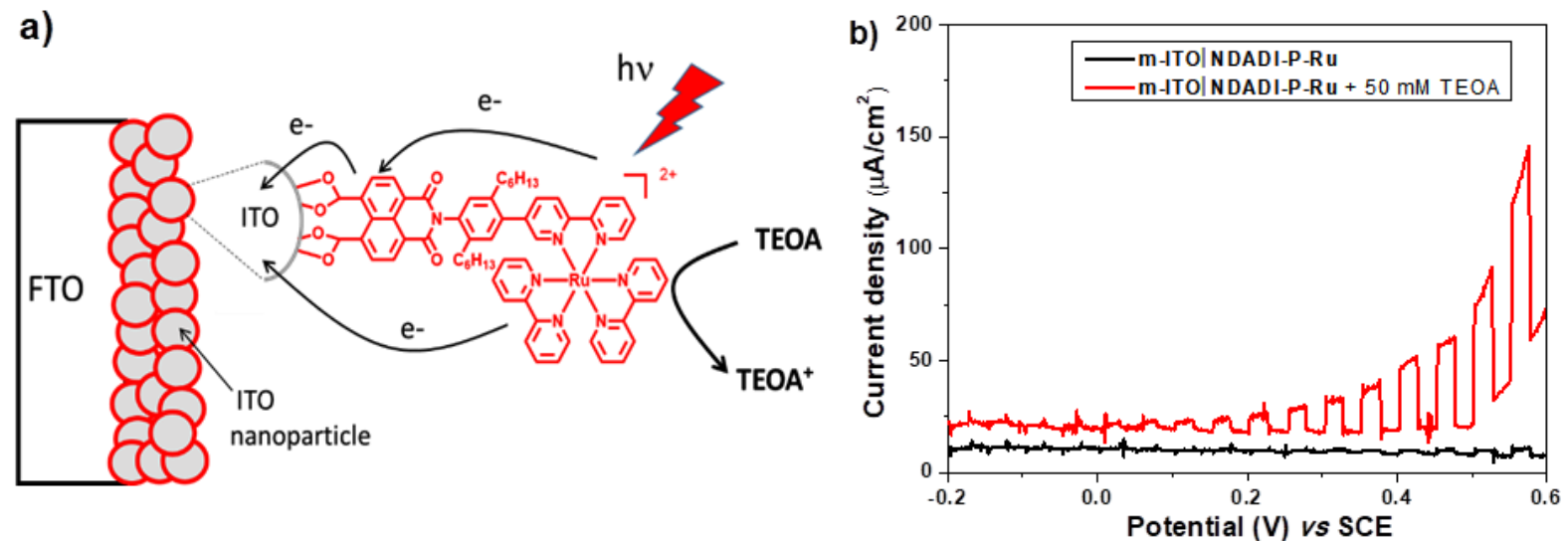

Figure 4. (a) Schematic presentation of working principle to generate photocurrent with the dyads grafted on meso-ITO in presence of TEOA, (b) Linear sweep voltammogram (LSV) under chopped visible light irradiation $\left(100 \mathrm{~mW} / \mathrm{cm}^{2}\right)$ for NDADI-P-Ru in absence (black 
trace) or in presence of $50 \mathrm{mM}$ TEOA (red trace) in $\mathrm{CH}_{3} \mathrm{CN}$ with $0.1 \mathrm{M}$ of $\mathrm{Bu}_{4} \mathrm{NPF}_{6}$ as supporting electrolyte. Scan rate $=5 \mathrm{mV} / \mathrm{sec}$.

Interestingly, when the model RuP complex was subjected to LSV under chopped visible light irradiation, under the same conditions, almost no photocurrent modulation could be measured, demonstrating that the NDADI plays a crucial role in the photocurrent production process (Figure S5). This is certainly the result of faster charge recombination as demonstrated by Meyer and co-workers for $\mathrm{Ru}$ complex immobilized on nano-ITO electrode. ${ }^{[10]}$

\section{Photocatalytic experiments}

From the above studies, it is clear that the NDADI-P-Ru can undergo photoinduced electron transfer, which is an important preliminary step to subsequently introduce the oxidized ruthenium complex into a catalytic oxidation process. Accordingly, the triad was prepared to investigate the possibility to oxidize alcohol substrates via activation of the TEMPO catalyst. Preliminary experiments were first carried out with a simple TEMPO catalyst in solution in order to determine suitable conditions to run the catalytic tests (Figure 1). In agreement with previous studies, we found that TEMPO very efficiently catalyses pmethoxy-benzyl alcohol (MeO-BA) into p-methoxy-benzaldehyde in carbonate buffer at $\mathrm{pH}$ $=10 .{ }^{[23]}$ The $\mathrm{pH}$ dependence of the photocatalysis was not investigated in this study. Optimal value is a trade-off between fast catalysis $v s$. the rate of desorption, which both increase with pH. Indeed, the cyclic voltammogram of TEMPO in buffer solution spans a reversible oxidation wave at $0.62 \mathrm{~V} v s$. SCE attributed to the formation of the oxoammonium in TEMPO (Figure S6). The addition of MeO-BA in the electrolyte leads to a huge and irreversible catalytic wave indicating that a chemical process is coupled with the electrochemical formation of the oxoammonium. In these conditions, the onset potential of the catalytic wave can be estimated to $0.55 \mathrm{~V}$ vs. SCE. Having found suitable catalytic conditions for benzyl-alcohol oxidation with TEMPO, we turned our attention to the study of the photocatalytic properties of the triad NDADI-P-Ru-TEMPO. The linear scan voltammetry with chopped light excitation of m-ITO|NDADI-P-Ru-TEMPO was therefore carried out in presence of $50 \mathrm{mM} \mathrm{MeO}-\mathrm{BA}$ by sweeping the potential from -0.2 to $+0.60 \mathrm{~V}$ vs. SCE in carbonate buffer solution $(\mathrm{pH}=10)$. The voltammogram on Figure 5 shows that light illumination induces a clear increasing photocurrent response starting from the applied 
potential of $0.2 \mathrm{~V} v s$. SCE, appearing thus at a $350 \mathrm{mV}$ lower potential than with the electrochemically assisted catalysis (Figure S6). The steadily increasing background current above $0.4 \mathrm{~V}$ can be interpreted as the superimposition of the photocurrent with the current coming from the direct electrochemical oxidation of the triad by the applied potential. In absence of MeO-BA in the electrolyte, the voltammogram is very different. First of all, the intensity of the photocurrent is much lower. Secondly, the magnitude of the photocurrent hardly increases upon increasing applied bias and finally there are significant spikes at the beginning (anodic) and at this end (cathodic) of the light irradiation sequence. The anodic spike certainly result of charging the cell after electron injection into ITO nanoparticles, then the current decays to a steady-state level close to zero because the photogenerated holes cannot be consumed by a species in the solution. The negative discharging current spike when the light is turned off is due to the back electron transfer of the electrons in ITO with holes on $\mathrm{Ru}^{\mathrm{III}}$ or $\mathrm{TEMPO}^{+}$.
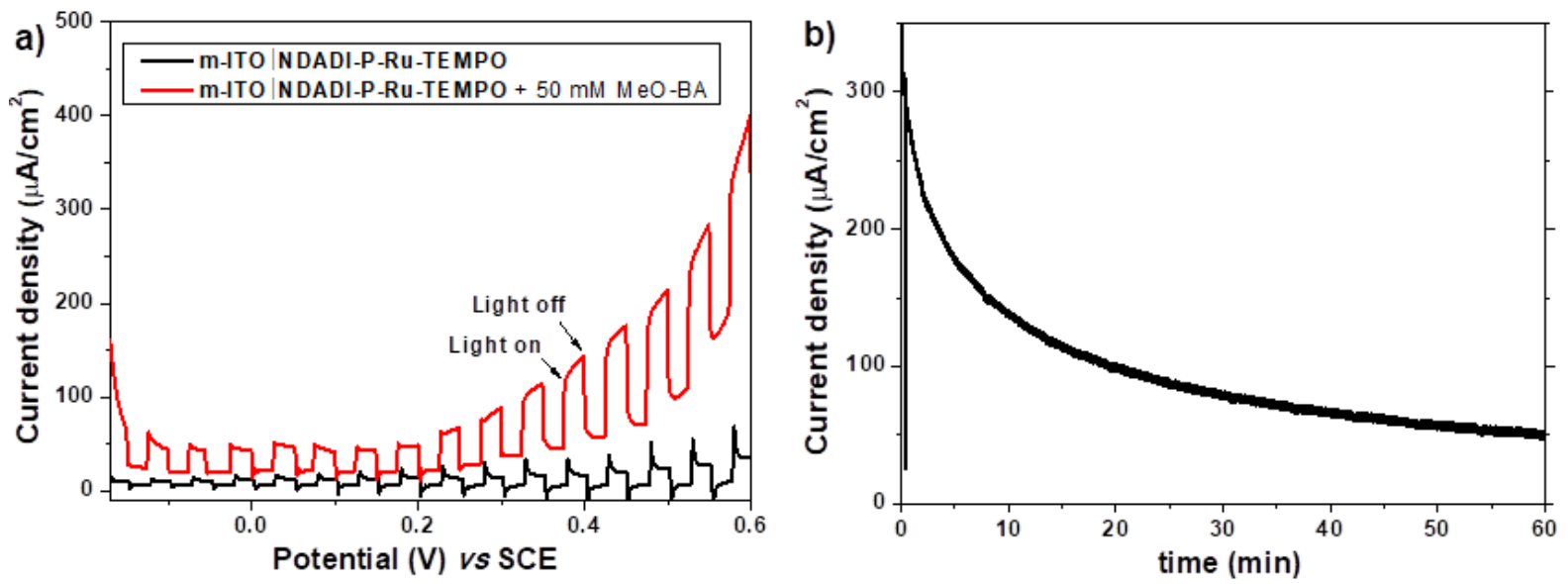

Figure 5. a) Linear sweep voltammograms under chopped light irradiation of NDADI-P-RuTEMPO in the absence (black trace) and in presence of $50 \mathrm{mM}$ of MeO-BA (red trace) in carbonate buffer at $\mathrm{pH}=10.0 \mathrm{~b}$ ) Long term photolysis experiment with the above conditions recorded under AM 1.5 irradiation for 1 hour at $0.4 \mathrm{~V}$ vs SCE applied potential. Scan rate $=5$ $\mathrm{mV} / \mathrm{sec}$.

In a second experiment, long term photocatalytic measurements were undertaken at different constant applied potentials $(0.2 \mathrm{~V}, 0.3 \mathrm{~V}$ and $0.4 \mathrm{~V} v s$. SCE) for 2 hours and the products formed into the electrolyte were analysed by gas chromatography (GC). These experiments were done in triplicate, the results are summarized in Table 2 and the photocurrent density curves as a function of time are gathered in Figure 5b and Figure S7. The decrease of the photocurrent as a function of the time is quite usual behaviour in 
DSPECs and can be attributed to leaching of the molecular system from the electrode and to photoinduced proton intercalation, which induces electron trapping in the oxide. ${ }^{[25]}$ Decomposition of the oxidized ruthenium complex is another possible source of degradation of the photocurrent. The initial (after $5 \mathrm{~min}$ of illumination) photocurrent density measured at respective $0.2 \mathrm{~V}, 0.3 \mathrm{~V}$ and $0.4 \mathrm{~V} v s$. SCE applied potentials were $45 \mu \mathrm{A} / \mathrm{cm}^{2}, 110 \mu \mathrm{A} / \mathrm{cm}^{2}$ and $180 \mu \mathrm{A} / \mathrm{cm}^{2}$. Although the goal of this work was not to break any photocatalytic record with the present system, these values compared well with previously reported DSPEC for alcohol oxidation with ruthenium based catalysts. ${ }^{[26]}$ For all the photolysis experiments, the only detected product was methoxy-benzaldehyde and no trace of methoxy-benzoic acid was found in the GC analyses. When the long term photocatalysis was carried out at bias potential $0.4 \mathrm{~V}$ vs. SCE, there was an initial average photocurrent density around $180 \mu \mathrm{A} / \mathrm{cm}^{2}$ which dropped to $80 \mu \mathrm{A} / \mathrm{cm}^{2}$ within the first 30 minutes. After $1 \mathrm{~h}$ of photocatalytic experiments average photocurrent density drops down to $50 \mu \mathrm{A} / \mathrm{cm}^{2}$ and after $2 \mathrm{~h}$ of photocatalytic experiments hardly any photocurrent was found to be left (Figure 5). To calculate the turnover number (TON), the loading of NDADI-P-Ru and NDADI-P-Ru-TEMPO on ITO electrode was determined by a desorption experiment with a solution of tetrabutylammonium hydroxide solution followed by the quantification of the desorbed compound by recording the absorbance of the resulting solution. For NDADI-P-Ru and NDADI-P-Ru-TEMPO, the loading was found to be $79 \pm 310^{-9} \mathrm{~mol} \mathrm{~cm}^{-2}$ and $65 \pm 210^{-9} \mathrm{~mol} \mathrm{~cm}^{-2}$ respectively through desorption method which is found to be significantly higher than that of the value obtained from electrochemical method. This discrepancy shows that the triads chemisorbed on the ITO film are not all electronically accessible and only a fraction (about 17\%) is involved in the photocatalysis. Accordingly, the TON values were calculated from the amount of photocatalysts measured by the electrochemical method, which is the amount of active species and in parentheses also from the desorption method, which corresponds the total amount loaded on the electrode surface (Table 2).

Table 2. Photocatalytic performances of NDADI-P-Ru-TEMPO and NDADI-P-Ru recorded upon photolysis under AM $1.5\left(100 \mathrm{~mW} / \mathrm{cm}^{2}\right)$ in $0.1 \mathrm{M}$ carbonate buffer $(\mathrm{pH}=10)$ with $50 \mathrm{mM}$ of MeO-BA.

\begin{tabular}{|c|c|c|c|c|c|c|}
\hline Compound & Entry & $\begin{array}{c}\text { Bias potential } \\
\text { vs. SCE }(\mathrm{V})\end{array}$ & $\begin{array}{c}\text { Duration } \\
(\mathrm{h})\end{array}$ & $\begin{array}{c}\text { Produced } \\
\text { aldehyde }(\mathrm{nmol})\end{array}$ & TON* & $\begin{array}{c}\text { FE } \\
(\%)\end{array}$ \\
\hline
\end{tabular}




\begin{tabular}{|c|c|c|c|c|c|c|}
\hline \multirow[t]{5}{*}{\begin{tabular}{|c|} 
NDADI-P- \\
Ru-TEMPO
\end{tabular}} & 1 & 0.2 & 2 & 742 & $\begin{array}{c}64 \pm 4 \\
(11 \pm 1)\end{array}$ & $75 \pm 3 \%$ \\
\hline & 2 & 0.3 & 2 & 1370 & $\begin{array}{l}122 \pm 4 \\
(21 \pm 1)\end{array}$ & $58 \pm 2 \%$ \\
\hline & 3 & \multirow[t]{3}{*}{0.4} & 2 & 2163 & $\begin{array}{c}191 \pm 2 \\
(33 \pm 1)\end{array}$ & $57 \pm 3 \%$ \\
\hline & 4 & & 1.5 & 2043 & $\begin{array}{l}180 \pm 4 \\
(31 \pm 1)\end{array}$ & $70 \pm 3 \%$ \\
\hline & 5 & & 1 & 1662 & $\begin{array}{l}151 \pm 4 \\
(26 \pm 1)\end{array}$ & $80 \pm 5 \%$ \\
\hline NDADI-P-Ru & 1 & 0.4 & 2 & 17 & $\begin{array}{c}9 \pm 2 \\
(1.5 \pm 0.5)\end{array}$ & $28 \pm 2 \%$ \\
\hline
\end{tabular}

* TON calculated from the catalyst amount determined by electrochemical and in parentheses from the desorption experiments (see text).

When the experiment was run at $0.4 \mathrm{~V} v$ s. SCE, a TON of 191(33) with a faradaic efficiency (FE) of $57 \%$ were measured, while at the lower bias potentials of $0.2 \mathrm{~V}$ and $0.3 \mathrm{~V} v s$. SCE respectively, the TONs were diminished to 64(11) and 122(21), while the FE were constant and even increased to $73 \%$ and $58 \%$. It can be observed that decreasing the bias potential induces a drop of the TON. This result can be explained by the fact that the charge collection efficiency by the electrode increases as the applied potential is more positive, because the driving force to extract the electron from the reduced NDADI or to inject an electron into ITO is larger. The photocatalytic performances were also measured for different time lengths at a bias potential of $0.4 \mathrm{~V} v s$. SCE (Table 2). Interestingly, the FE increases from $57 \%$ to $80 \%$ respectively when the photolysis duration decreases from 2 hours to 1 hour. The decrease of FE and TON upon increasing the photocatalysis duration can be justified by the detachment of the molecular triad from the ITO surface and can be confirmed by naked eyes, because the coloration of the electrodes has significantly diminished after the experiments. Indeed, it is known that carboxylic acid anchors are not very stable in basic conditions. As a control experiment LSV of m-ITO|NDADI-P-Ru electrode was carried out in absence and presence of MeO-BA was done which concludes very negligible photoresponse (Figure S8). After $2 \mathrm{~h}$ of photocatalysis by applying a bias potential of $0.4 \mathrm{~V} v$ s. SCE only a little amount of methoxy-benzaldehyde was found, corresponding to a TON of $9(1.5)$ and a FE of $28 \pm 3 \%$, 
which are much lower of those measured with the triad. In a final experiment, the TEMPO catalyst was added into the solution to function with the dyad NDADI-P-Ru grafted on ITO in order to investigate the effect of linking the catalyst to the dye. Toward this goal, LSV were recorded with m-ITO|NDADI-P-Ru electrode in presence of $50 \mathrm{mM}$ MeO-BA after addition of different concentrations of TEMPO into the electrolyte (concentrations from 0.1 $\mathrm{mM}$ to $10 \mathrm{mM}$ ) (Figure S9). Interestingly, there no significant photoresponse of the system even in presence of $10 \mathrm{mM}$ TEMPO. These conditions correspond to a quantity of catalyst, which is $1.5 \times 10^{5}$ folds higher than that immobilized on the electrode with the triad NDADIP-Ru-TEMPO. This experiment definitely confirms that the covalent attachment of the catalyst to the dye is far superior in term of efficiency and is fundamental to attain a significant catalytic activity. This can be understood as the mean distance between the ruthenium complex to the TEMPO is much larger when the TEMPO is in solution compare to the situation when it is linked as in NDADI-P-Ru-TEMPO. As a consequence, the hole shift reaction is much more favourable in NDADI-P-Ru-TEMPO.

\section{Transient absorption spectroscopy}

The light-induced reactions of m-ITO|NDADI-P-Ru and m-ITO|NDADI-P-Ru-TEMPO were investigated by femto-second transient absorption spectroscopy ( $f s$-TAS). In acetonitrile solution, NDADI-P-Ru and NDADI-P-Ru-TEMPO showed the characteristics of the longlived MLCT excited state of the Ru-polypyridine unit, which did not decay significantly on the time scale of $f s$-TA ( $<7 \mathrm{~ns}$; Figure S11), consistent with an MLCT lifetime of $500 \mathrm{~ns}$ in acetonitrile solution). When they were bound to ITO instead, the MLCT absorption bands around $380 \mathrm{~nm}$ and $>500 \mathrm{~nm}$ decayed rapidly, with half-lives of approximately $160 \mathrm{ps}$ and 80 ps for m-ITO|NDADI-P-Ru and m-ITO|NDADI-P-Ru-TEMPO, respectively (Figure 6). The kinetic traces are very non-exponential and decay in an approximately linear fashion when plotted on a logarithmic time scale. This reflects the kinetic heterogeneity typically encountered for molecule-semiconductor charge transfer reactions. ${ }^{[27]}$ While the traces could be reproduced by a stretched exponential function with a small $\beta$-value $(\beta<0.2)$, this provides little added insight for the present discussion compared to a simple comparison of half-lives and inspection of the kinetic traces. The rapid MLCT quenching thus observed could be due to electron transfer either directly to ITO, or via the NDADI unit as a short-lived intermediate. In the latter case, the reaction of reduced NDADI must be much faster than its 
production, as no reduced NDADI is observed (i.e. a strong and narrow band expected around $420 \mathrm{~nm}^{[28]}$ ). To determine if ITO or NDADI is the main electron acceptor, the compounds were bound to $\mathrm{Al}_{2} \mathrm{O}_{3}$ instead. For this material, electron injection into the conduction band is not energetically possible, while the NDADI unit should be the same as when bound to ITO. The MLCT state was significantly less quenched on a $<7$ ns timescale (not shown), which suggests direct electron transfer to ITO as the main quenching mechanism, but does not totally exclude a concomitant electron transfer via NDADI as a minor process. It is intriguing that the $\mathrm{Ru}$ dye could be so efficiently quenched by electron injection into ITO although it is not directly bound to it, owing to the well-known exponential dependence of outer sphere electron transfer on the distance. ${ }^{[29]}$ Indeed, it is well accepted that efficient electron injection into the conduction band of a n-SC requires either a close distance between the dye and the n-SC or a sizable electronic coupling. In the present case, we cannot exclude that the molecular triad is bent on the ITO bringing thus the Ru complex close to the surface as it was lying perpendicularly. Moreover, the driving force for electron injection in ITO is much larger (about $-1.2 \mathrm{eV}$ when ITO is bias at $0.4 \mathrm{~V}$ vs. SCE) than electron transfer to NDADI and could also explain this result. Interestingly, the presence of the NDADI slows down charge recombination as the reference RuP complex does not give photocurrent (Figure S5) upon photoirradiation in presence of TEOA. This most likely results from slower charge recombination after electron injection compare when the dye is in close contact with the conductor (case of RuP). ${ }^{[10]}$ The somewhat shorter MLCT lifetime for $\mathbf{m}$ ITO|NDADI-P-Ru-TEMPO, in spite of a somewhat lower driving force for electron transfer to ITO, could in principle be due to a parallel oxidative quenching by TEMPO, but as no MLCT quenching was observed for the compound in neat acetonitrile, we believe that the lifetime difference is rather due to small differences in binding geometry of the molecule to the ITO surface. MLCT quenching results in formation of the oxidized $\mathrm{Ru}^{\mathrm{III}}$ unit, which is seen as a similar bleach of the $\mathrm{Ru}^{\mathrm{II}}$ ground state around $450 \mathrm{~nm}$ as for the MLCT state, while there is only weak positive absorption in the wavelength range examined. In m-ITO|NDADI$\mathbf{P}-\mathbf{R u}, \mathrm{Ru}^{\mathrm{III}}$ recombines with ITO electrons with a half-life of ca. $325 \mathrm{ps}$, which is observed as a bleach recovery in Figure 6. The corresponding recovery in m-ITO|NDADI-P-RuTEMPO gave a half-life of 280 ps; the somewhat faster recovery could be due to hole transfer to the TEMPO unit in parallel to charge recombination, but slight differences in binding geometry or $\mathrm{Ru}^{\mathrm{III/II}}$ potential may also explain this result. The absorption spectrum of $\mathrm{TEMPO}^{\bullet}$ and $\mathrm{TEMPO}^{+}$are both very weak and covered by the $\mathrm{Ru}^{\mathrm{II}}$ absorption, ${ }^{\left[{ }^{30]}\right.}$ thus $f s^{-}$ 
TAS could not give direct evidence for oxidation of TEMPO. Nevertheless, $f_{s}$-TAS gives clear evidence for rapid electron transfer from the excited $\mathrm{Ru}$ unit to ITO as the first step in the photocatalytic process.
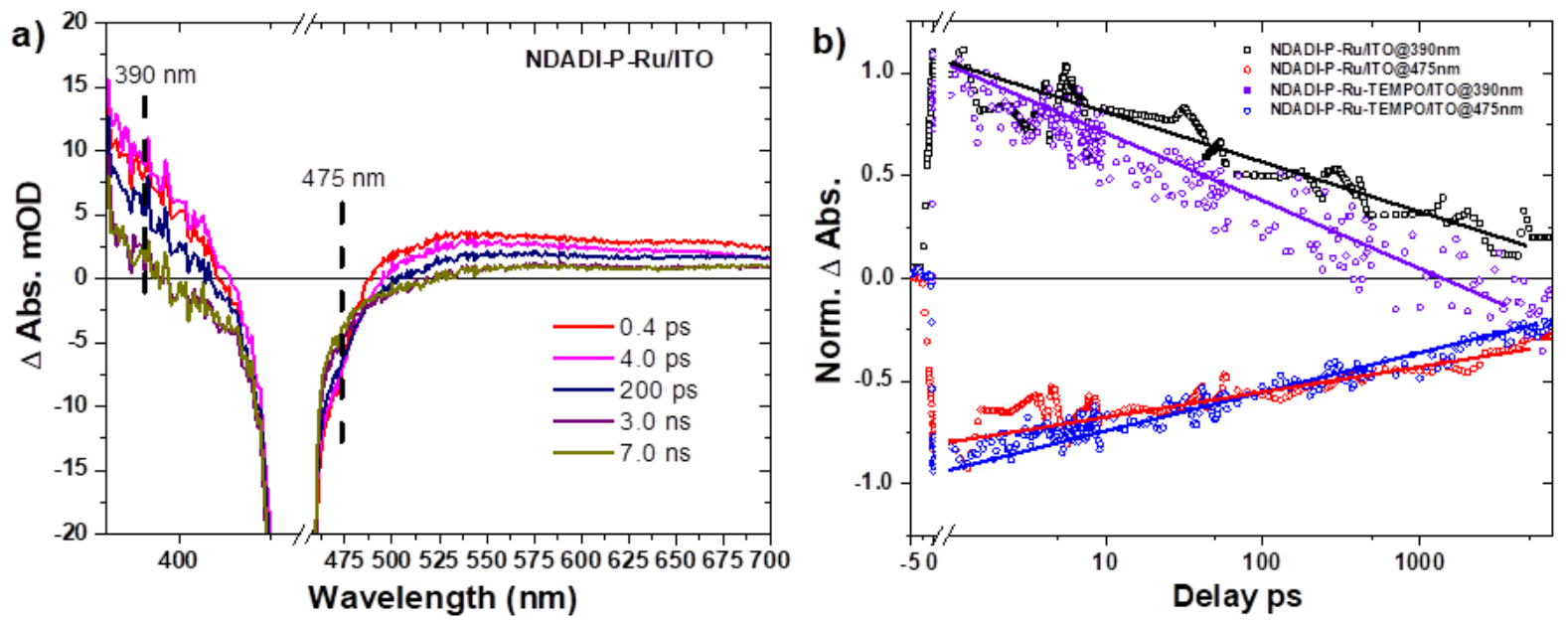

Figure 6. Fs-TAS data for ITO|NDADI-P-Ru and ITO|NDADI-P-Ru-TEMPO. a) TAS spectra for ITO|NDADI-P-Ru at 0.4 ps $-7 \mathrm{~ns}$ after laser excitation at $455 \mathrm{~nm}$ with ca. 120 fs laser pulses (corresponding figure for ITO|NDADI-P-Ru-TEMPO is given in the SI). Note that the sharp, negative feature at $450-460 \mathrm{~nm}$ is due to scattered excitation light. b) TAS time traces at $390 \mathrm{~nm}$ and $475 \mathrm{~nm}$ both compounds, with approximate first half-life values indicated; the lines are just guides for the eye.

\section{Conclusion}

In summary, a hybrid photocatalytic system was successfully fabricated using an original strategy based on the immobilization on nano-ITO electrode of a molecular triad featuring and a TEMPO catalyst for alcohol oxidation. This design is different from the classically used systems made of sensitizer linked to a ruthenium catalyst involved in $\mathrm{TiO}_{2}$ based DSPECs. ${ }^{[26,31]}$ The basic idea of this study was to explore whether a hybrid system made of a covalent molecular assembly of the type "conductor-A-Dye" could generate oxidizing equivalents to be subsequently involved in an oxidation catalytic reaction. In our specific design, NDADI acts as the electron acceptor to the neighbouring $\mathrm{Ru}$ dye and enables a photoinduced charge separation to generate the electron/hole pair ITO(e-)/Ru ${ }^{\text {III }}$. The photogenerated hole is subsequently used to activate an oxidation catalyst, while ITO 
electrode is used to scavenge the electron. This rarely explored approach is valuable because it makes it possible to consider the oxidative quenching of a dye displaying a high oxidation redox potential by appending a strong electron acceptor such as naphthalene diimide substituted by electron withdrawing groups. ${ }^{[8]}$ In addition, this study shows that the classically used ruthenium based catalyst can be advantageously replaced by an organocatalyst such as TEMPO since significant photocurrent densities were measured in the order of $180 \mu \mathrm{A} / \mathrm{cm}^{2}$ in our photoelectrocatalyic cell. The important finding of this study is that the photoinduced electron transfer step from the dye to the acceptor must be fast and efficient to outcompete with electron injection. Improvements of the present system can be made by replacing the NDADI by an easier to reduce electron acceptor, changing the ruthenium complex with a higher reducing excited state, or by a broader light collector such as an organic dye, and by grafting the molecular system with more stable anchoring groups such as phosphonic or hydroxamic acids. ${ }^{[32]}$ In the future, this type of hybrid photoanode is intended to be connected to a photocathode to perform proton, carbon dioxide or nitrogen reduction catalysis in which the electrons produced at the photoanode will be energized by the photon absorption from the second light collector. The latter photocathode can be designed with the similar approach as that proposed here or with a regular low bandgap semiconductor such as $\mathrm{CuInGaSe}{ }_{2}{ }^{[33]}$ or $\mathrm{Cu}_{2} \mathrm{O}^{[34]}$ coated with a suitable catalyst. We currently work along these directions.

\section{Experimental sections}

\section{General}

${ }^{1} \mathrm{H},{ }^{13} \mathrm{C}$ and spectra were recorded on an AVANCE 300 UltraShield BRUKER and AVANCE 400 BRUKER. Chemical shifts for ${ }^{1} \mathrm{H}$ and ${ }^{13} \mathrm{C}$ NMR spectra are referenced relative to residual protium in the deuterated solvent $\left(\mathrm{CDCl}_{3} \delta=7.26 \mathrm{ppm}\right.$ for ${ }^{1} \mathrm{H}$ and $\delta=77.16 \mathrm{ppm}$ for ${ }^{13} \mathrm{C}$; DMSO- $\mathrm{d}_{6} \delta=2.50 \mathrm{ppm}$ for ${ }^{1} \mathrm{H}$ and $\delta=39.52 \mathrm{ppm}$ for ${ }^{13} \mathrm{C}$ ). NMR spectra were recorded at room temperature, chemical shifts are written in ppm and coupling constants in Hz. Highresolution mass (HRMS) spectra were obtained by electrospray ionization coupled with high resolution ion trap orbitrap (LTQ-Orbitrap, ThermoFisher Scientific) working in ion-positive or ion-negative mode. Elemental Analyser, Model FLASH 2000 (Thermo Fisher Scientific) with PC based data system, Eager Xperience for WindowsTM and a Mettler Toledo XP6 Micro Balance. This instrument automatically determines carbon, hydrogen and nitrogen. 
Combustion of the sample, separation of the combustion gases and measurement by thermal conductivity are all carried out in the dynamic mode. UV-visible absorption spectra were recorded on a Variant Cary 300, using $1 \mathrm{~cm}$ path length cells. Chemicals were purchased from Sigma-Aldrich or Alfa Aesar and used as received. Thin-layer chromatography (TLC) was performed on aluminium sheets precoated with Merck 5735 Kieselgel 60F254. Column chromatography was carried out either with Merck 5735 Kieselgel 60F (0.040-0.063 mm mesh). Sephadex L20 was used for size-exclusion chromatographic separation.

\section{Electrochemical and photoelectrochemical (PEC) measurements}

Electrochemical measurements were made under an argon atmosphere in the dry acetonitrile with $0.1 \mathrm{M} \mathrm{Bu}_{4} \mathrm{NPF}_{6}$. Cyclic voltammetry experiments were performed by using a SP300 Bio-Logic potentiostat/galvanostat. A standard three-electrode electrochemical cell was used. All potentials are quoted relative to SCE. The working electrode was a glassy carbon disk and the auxiliary electrode was a Pt wire. To investigate the molecular photocathode, PEC measurements were carried out in a single component setup fitted with working electrode (meso-ITO sensitized with either dyad or triad) saturated calomel electrode and Pt-mesh were used as reference and counter electrode, respectively. The area of working electrode were used either $0.25 \mathrm{~cm}^{2}$ or $1.0 \mathrm{~cm}^{2}$ and photoresponse were reported in terms current density $/ \mathrm{cm}^{2}$. Before every experiment, the PEC cell was degassed by Ar for at least $15 \mathrm{~min}$. For long term photocatalysis $1.0 \mathrm{~cm}^{2}$ electrodes were used. A white LED PAR38 lamp (17 $\mathrm{W}, 5000 \mathrm{~K}$ ) was used as a light source and the distance between the light source and photoelectrochemical cell was always $12 \mathrm{~cm}$ to maintain the light power to be 1 sun. The power of the lamp is about $1000 \mathrm{~W} / \mathrm{m}^{2}$ as determined with a calibrated silicon cell.

\section{Product analysis through GC}

After the finishing of long term photocatalysis the compound was extracted with dichloromethane and then that extracted portion was analyzed through gas chromatography (Agilent Technologies 7890B GC) system equipped with a thermal conductivity detector. Calibration curves for para-Methoxy benzylalcohol (MeO-BA) and para-Methoxy benzaldehyde were determined separately by injecting known volumes of them respectively. Generated product from long term photocatalysis were quantified through that calibration curve. From product quantification, TON is calculated as follow:

$$
\mathrm{TON}=n_{\text {product }} / n_{\text {catalyst,film }}
$$




\section{Preparation of the photocathode}

FTO conductive glass substrates (F-doped $\mathrm{SnO}_{2}$ ) were purchased from Pilkington (TEC8). Three successive layers of mesoporous ITO were then screen printed using a colloidal paste of ITO with 10 -minute long drying steps at $100^{\circ} \mathrm{C}$ between each layer. The obtained substrates were then sintered at $450^{\circ} \mathrm{C}$, following a progressive heating ramp $\left(325^{\circ} \mathrm{C}\right.$ for 5 $\min , 375^{\circ} \mathrm{C}$ for $5 \mathrm{~min}, 450^{\circ} \mathrm{C}$ for $30 \mathrm{~min}$ ). Meso-ITO films were prepared with two different surface area coverage i.e. $0.25 \mathrm{~cm}^{2}$ and $1.0 \mathrm{~cm}^{2}$. Subsequently, the ITO films were sensitized by dipping the films into a $0.2 \mathrm{~mm}$ methanol solution (first the dyads were make dissolved in few drops of dichloromethane and then methanol were used to maintain the concentration of dyeing bath) for overnight. The photoelectrodes were rinsed with methanol to remove excess weakly deposited dye on the surface, then dried under a nitrogen flow and in principle is ready to be tested.

\section{Ultrafast laser spectroscopy}

The preparation of NDADI-P-Ru and NDADI-P-Ru-TEMPO sensitized films for the femtosecond transient absorption measurements were similar to ones used for the PEC experiments, but with a thinner layer (ca. $1 \mathrm{~mm}$ ) to have sufficient transparency for pumpprobe measurements. Femto-second transient absorption spectroscopy ( $f s$-TAS) was performed probing in the UV-Vis region using a Newport TAS. A Coherent Libra Ti:sapphire amplifier $(1.5 \mathrm{~mJ}, 3 \mathrm{kHz}, 800 \mathrm{~nm}$, fwhm $40 \mathrm{fs})$ was used and split into pump and probe beams. An excitation wavelength of $440 \mathrm{~nm}$ was generated by directing the pump beam into the optical parametric amplifiers (TOPAS-Prime and NIRUVVIS, Light Conversion) and then focused and centered on the dry films with a pump power adjusted to $350 \mu \mathrm{W}$. The 800 $\mathrm{nm}$ fundamental of the amplifier was focused on $\mathrm{a} \mathrm{CaF}_{2}$ crystal (Newport TAS), generating the white light supercontinuum probe. A silicon diode array (Newport custom made) was used to record the probe spectrum. A mechanical chopper blocked every other pump pulse, and the transient absorption at each time point was calculated for an average of $1000 \mathrm{~ms}$ chopped/un-chopped pulse pairs. To record the transient absorption spectra at different time points, an optical delay line was used to scan the delay of the probe beam relative to the pump beam from -5 ps to $7 \mathrm{~ns}$. A total of ten scans were collected and averaged for each sample. Prior to analysis, the data was corrected for the spectral chirp using Surface Xplorer 4.2, where single wavelength fits were also performed. Ref 


\section{Acknowledgements}

Région des Pays de la Loire is gratefully acknowledged for the financial support of the project "Hybrid Z- scheme" via "LUMOMAT" RFI program. L.H. acknowledges support from the Knut and Alice Wallenberg Foundation (project no. 2019.0071). Robin Tyburski is acknowledged for helping in ultrafast laser spectroscopy measurement. The authors greatly acknowledge J. Hémez and L. Arzel (AMaCC platform, CEISAM UMR CNRS 6230, University of Nantes) for the mass spectrometry analyses.

Supporting information available: Synthetic procedures and characterizations of the new compounds, absorption spectra of the compounds on nano-ITO electrode, cyclic voltamogramms in solution and on nano-ITO electrodes, additional transient absorption spectroscopy spectra, additional of linear sweep voltammograms experiments, additional femtosecond transient absorption spectroscopy spectra and ${ }^{1} \mathrm{H}$ and ${ }^{13} \mathrm{C}$ spectra of the new compounds.

\section{References:}

[1] a) V. Balzani, A. Credi, M. Venturi, ChemSusChem 2008, 1, 26-58; b) J. J. Concepcion, R. L. House, J. M. Papanikolas, T. J. Meyer, Proc. Natl. Acad. Sci. U. S. A. 2012, 109, 15560-15564; c) N. S. Lewis, D. G. Nocera, Proc. Natl. Acad. Sci. U. S. A. 2006, 103, 15729-15735; d) M. G. Walter, E. L. Warren, J. R. McKone, S. W. Boettcher, Q. Mi, E. A. Santori, N. S. Lewis, Chem. Rev. 2010, 110, 6446-6473.

[2] a) A. Eftekhari, V. J. Babu, S. Ramakrishna, Internat. J. Hydrogen Energy 2017, 42, 11078-11109; b) B. Alfaifi, H. Ullah, S. Alfaifi, A. Tahir, T. Mallick, Photoelectrochemical solar water splitting: From basic principles to advanced devices. 2018; Vol. 2; c) X. Yang, D. Wang, ACS Appl. Energy Mater. 2018, 1, 6657-6693.

[3] a) D. Zhang, J. Shi, W. Zi, P. Wang, S. Liu, ChemSusChem 2017, 10, 4324-4341; b) K. Sun, S. Shen, Y. Liang, P. E. Burrows, S. S. Mao, D. Wang, Chem. Rev. 2014, 114, 86628719.

[4] D. Bae, B. Seger, P. C. K. Vesborg, O. Hansen, I. Chorkendorff, Chem. Soc. Rev. 2017, 46, 1933-1954. 
[5] D. L. Ashford, M. K. Gish, A. K. Vannucci, M. K. Brennaman, J. L. Templeton, J. M. Papanikolas, T. J. Meyer, Chem. Rev. 2015, 115, 13006-13049.

[6] a) D. Wang, R. N. Sampaio, L. Troian-Gautier, S. L. Marquard, B. H. Farnum, B. D. Sherman, M. V. Sheridan, C. J. Dares, G. J. Meyer, T. J. Meyer, J. Am. Chem. Soc. 2019, 141, 7926-7933; b) D. Wang, B. H. Farnum, C. J. Dares, T. J. Meyer, J. Chem. Phys. 2020, 152, 244706; c) B. H. Farnum, K.-R. Wee, T. J. Meyer, Nature Chem. 2016, 8, 845-852; d) B. Shan, B. H. Farnum, K.-R. Wee, T. J. Meyer, J. Phys. Chem. C 2017, 121, 5882-5890.

[7] R. van de Krol, Photoelectrochemical Hydrogen Production. 2012.

[8] J. Shukla, P. Mukhopadhyay, Eur. J. Org. Chem. 2019, 2019, 7770-7786.

[9] a) J. Jiang, J. R. Swierk, K. L. Materna, S. Hedström, S. H. Lee, R. H. Crabtree, C. A. Schmuttenmaer, V. S. Batista, G. W. Brudvig, J. Phys. Chem. C 2016, 120, 28971-28982; b) A. Orbelli Biroli, F. Tessore, G. Di Carlo, M. Pizzotti, E. Benazzi, F. Gentile, S. Berardi, C. A. Bignozzi, R. Argazzi, M. Natali, A. Sartorel, S. Caramori, ACS Appl. Mater. Interfaces 2019, 11, 32895-32908; c) L. Wang, D. W. Shaffer, G. F. Manbeck, D. E. Polyansky, J. J. Concepcion, ACS Catal. 2020, 10, 580-585; d) J. R. Swierk, D. D. Méndez-Hernández, N. S. McCool, P. Liddell, Y. Terazono, I. Pahk, J. J. Tomlin, N. V. Oster, T. A. Moore, A. L. Moore, D. Gust, T. E. Mallouk, Proc. Natl. Acad. Sci. U.S.A. 2015, 112, 1681-1686; e) J. T. Kirner, J. J. Stracke, B. A. Gregg, R. G. Finke, ACS Appl. Mater. Interfaces 2014, 6, 1336713377; f) Y. K. Eom, L. Nhon, G. Leem, B. D. Sherman, D. Wang, L. Troian-Gautier, S. Kim, J. Kim, T. J. Meyer, J. R. Reynolds, K. S. Schanze, ACS Energy Lett. 2018, 3, 21142119.

[10] a) B. H. Farnum, Z. A. Morseth, M. K. Brennaman, J. M. Papanikolas, T. J. Meyer, J. Phys. Chem. B 2015, 119, 7698-7711; b) B. H. Farnum, A. Nakada, O. Ishitani, T. J. Meyer, J. Phys. Chem. C 2015, 119, 25180-25187; c) R. J. Moerland, J. P. Hoogenboom, Optica 2016, 3, 112-117; d) Y. Wu, H. R. Wu, M. L. Wang, M. Lu, Q. L. Song, X. M. Ding, X. Y. Hou, Appl. Phys. Lett. 2007, 90, 154105.

[11] M. Skaisgirski, X. Guo, O. S. Wenger, Inorg. Chem. 2017, 56, 2432-2439.

[12] a) T. Edvinsson, C. Li, N. Pschirer, J. Schoeneboom, F. Eickemeyer, R. Sens, G. Boschloo, A. Herrmann, K. Muellen, A. Hagfeldt, J. Phys. Chem. C 2007, 111, 15137-15140; b) J. Fortage, M. Severac, C. Houarner-Rassin, Y. Pellegrin, E. Blart, F. Odobel, J. Photochem. Photobiol., A 2008, 197, 156-169; c) R. J. Kamire, K. L. Materna, W. L. Hoffeditz, B. T. Phelan, J. M. Thomsen, O. K. Farha, J. T. Hupp, G. W. Brudvig, M. R. Wasielewski, J. Phys. Chem. C 2017, 121, 3752-3764; d) R. J. Lindquist, B. T. Phelan, A. Reynal, E. A. Margulies, L. E. Shoer, J. R. Durrant, M. R. Wasielewski, J. Mater. Chem. A 2016, 4, 2880-2893; e) M. Planells, F. J. Cespedes-Guirao, A. Forneli, A. Sastre-Santos, F. Fernandez-Lazaro, E. Palomares, J. Mater. Chem. 2008, 18, 5802-5808; f) Y. Shibano, T. Umeyama, Y. Matano, H. Imahori, Org. Lett. 2007, 9, 1971-1974.

[13] B. Koz, S. Demic, S. Icli, Asian J. Chem. 2016, 28, 2755-2758.

[14] a) J. D. Blakemore, R. H. Crabtree, G. W. Brudvig, Chem. Rev. 2015, 115, 1297413005; b) R. Matheu, M. Z. Ertem, C. Gimbert-Suriñach, X. Sala, A. Llobet, Chem. Rev. 2019, 119, 3453-3471; c) L. Duan, L. Wang, F. Li, F. Li, L. Sun, Acc. Chem. Res. 2015, 48, 2084-2096.

[15] F. Wang, S. S. Stahl, Acc. Chem. Res. 2020, 53, 561-574.

[16] a) H. Sterckx, B. Morel, B. U. W. Maes, Angew. Chem. Int. Ed. 2019, 58, 7946-7970; Angew. Chem. 2019, 131, 8028-8055; b) J. E. Nutting, M. Rafiee, S. S. Stahl, Chem. Rev. 2018, 118, 4834-4885; c) R. Ciriminna, M. Pagliaro, Org. Process Res. Dev. 2010, 14, $245-$ 251.

[17] a) B. Mei, G. Mul, B. Seger, Adv. Sustainable Syst. 2017, 1, 1600035; b) S. Kampouri, K. C. Stylianou, ACS Catal. 2019, 9, 4247-4270; c) C. R. Lhermitte, K. Sivula, ACS Catal. 2019, 9, 2007-2017; d) K. Sayama, ACS Energy Lett. 2018, 3, 1093-1101; e) 
Lacey M. Reid, T. Li, Y. Cao, C. P. Berlinguette, Sustainable Energy Fuels 2018, 2, 19051927.

[18] a) R. Ciriminna, G. Palmisano, M. Pagliaro, ChemCatChem 2015, 7, 552-558; b) R. Ciriminna, M. Ghahremani, B. Karimi, M. Pagliaro, Chem. Open 2017, 6, 5-10.

[19] H. G. Cha, K.-S. Choi, Nature Chem. 2015, 7, 328.

[20] T. Li, T. Kasahara, J. He, K. E. Dettelbach, G. M. Sammis, C. P. Berlinguette, Nature Commun. 2017, 8, 390.

[21] X. Lu, N. Wu, B. Zhang, K. Deng, J. Coord. Chem. 2017, 70, 475-486.

[22] J. Warnan, V.-M. Guerin, F. B. Anne, Y. Pellegrin, E. Blart, D. Jacquemin, T. Pauporté, F. Odobel, J. Phys. Chem. C 2013, 117, 8652-8660.

[23] M. Rafiee, K. C. Miles, S. S. Stahl, J. Am. Chem. Soc. 2015, 137, 14751-14757.

[24] P. Kang, S. Zhang, T. J. Meyer, M. Brookhart, Angew. Chem. Int. Ed. 2014, 53, 87098713; Angew. Chem. 2019, 126, 8853-8857.

[25] a) N. S. McCool, J. R. Swierk, C. T. Nemes, T. P. Saunders, C. A. Schmuttenmaer, T. E. Mallouk, ACS Appl. Mater. Interfaces 2016, 8, 16727-16735; b) J. R. Swierk, N. S. McCool, T. P. Saunders, G. D. Barber, T. E. Mallouk, J. Am. Chem. Soc. 2014, 136, 1097410982.

[26] a) T. V. Pho, M. V. Sheridan, Z. A. Morseth, B. D. Sherman, T. J. Meyer, J. M. Papanikolas, K. S. Schanze, J. R. Reynolds, ACS Appl. Mater. Interfaces 2016, 8, 9125-9133; b) W. Song, A. K. Vannucci, B. H. Farnum, A. M. Lapides, M. K. Brennaman, B. Kalanyan, L. Alibabaei, J. J. Concepcion, M. D. Losego, G. N. Parsons, T. J. Meyer, J. Am. Chem. Soc. 2014, 136, 9773-9779; c) J. A. Treadway, J. A. Moss, T. J. Meyer, Inorg. Chem. 1999, 38, 4386-4387; d) D. Badgurjar, B. Shan, A. Nayak, L. Wu, R. Chitta, T. J. Meyer, ACS Appl. Mater. Interfaces 2020, 12, 7768-7776.

[27] a) J. Nelson, S. A. Haque, D. R. Klug, J. R. Durrant, Phys. Rev. B 2001, 63, 205321; b) L. D'Amario, L. J. Antila, B. Pettersson Rimgard, G. Boschloo, L. Hammarström, J. Phys. Chem. Lett. 2015, 6, 779-783.

[28] D. Gosztola, M. P. Niemczyk, W. Svec, A. S. Lukas, M. R. Wasielewski, J. Phys. Chem. A 2000, 104, 6545-6551.

[29] a) J. N. Clifford, E. Palomares, M. K. Nazeeruddin, M. Grätzel, J. Nelson, X. Li, N. J. Long, J. R. Durrant, J. Am. Chem. Soc. 2004, 126, 5225-5233; b) R. A. Marcus, N. Sutin, Biochim. Biophys. Acta 1985, 811, 265-322; c) J. Wiberg, T. Marinado, D. P. Hagberg, L. Sun, A. Hagfeldt, B. Albinsson, J. Phys. Chem. B 2010, 114, 14358-14363.

[30] J. C. Siu, G. S. Sauer, A. Saha, R. L. Macey, N. Fu, T. Chauviré, K. M. Lancaster, S. Lin, J. Am. Chem. Soc. 2018, 140, 12511-12520.

[31] a) A. K. Vannucci, J. F. Hull, Z. Chen, R. A. Binstead, J. J. Concepcion, T. J. Meyer, J. Am. Chem. Soc. 2012, 134, 3972-3975; b) P. Farràs, C. Di Giovanni, J. N. Clifford, P. Garrido-Barros, E. Palomares, A. Llobet, Green Chem. 2016, 18, 255-260; c) P. Farràs, C. Di Giovanni, J. N. Clifford, E. Palomares, A. Llobet, Coord. Chem. Rev. 2015, 304-305, 202208.

[32] K. L. Materna, R. H. Crabtree, G. W. Brudvig, Chem. Soc. Rev. 2017, 46, 6099-6110. [33] P. Palas Baran, R. Wang, E. Boutin, S. Diring, S. Jobic, N. Barreau, F. Odobel, M. Robert, Nature Commun. 2020, 11, 3499.

[34] M. Schreier, J. Luo, P. Gao, T. Moehl, M. T. Mayer, M. Grätzel, J. Am. Chem. Soc. 2016, 138, 1938-1946. 